consists of so many units; we have no organisation, and but scanty equipment; whilst many anomalies exist as to rank and the like. All these points have received, and are receiving, the attention of the Council. To our colleagues in the service we appeal, not only to join us and make our organisation as strong as possible, but, in every other way to render such assistance as will make the Volunteer Medical Service in all respects effective.

I am, Sirs, yours faithfully,

WM. Roвt, Sмite, M.D., D.Sc, F.R.S.ED.

Surg.-Maj. 3rd V. B., Queen's O wn (Roy. West Kent Regt.), Volunteer Medical Association,

26, King William Street, Strand, W.C., April 17th, 1888.

P.S.-I would add that a class has been formed for Volunteer medical officers, in preparation for the proficiency certificate, particulars of which can be obtained at the above office.

\section{IS PHOSPHORUS A CAUSE OF CANCER?}

\section{To the Editors of THE LANCET.}

SIrs,-Of late cancer has been, so to speak, more before us than ever; following closely on Sir James Paget's address we have had Mr. Haviland's notes on the geographical distribution of cancerous disease in the British Isles, with its indications of increase in cancer mortality, and of lesser mortality in limestone districts; we have had the treatment of cancer by lime salts, notably burned oyster shells, which in a way seems but a likely and fit method of supplying lime, perhaps needed, in districts where it does not so plentifully exist; we have had suggestions as to the almost probability that arsenic may in certain cases aggravate into existence cancerous disease; but we have not had, what I had looked for and hoped for, any suggestion as to the probabilities of any aggravation of the same kind caused by phosphorus. Arsenic has beon used for I cannot say how long a period in pharmacy, nor have $I$ at hand the means of referring back; but, in connexion with phosphorus, in the British Pharmacopoeias of 1864 and 1867 it existed, "to be used in the preparation of the dilute phosphoric acid," and the only preparations containing phosphorus were the dilute acid and the phosphates of ammonia of lime, of soda, and of iron, the syrup of the phosphate of iron, and the antimony powder. No phosphorus oil and no phosphorus pills in their hundred and one variety were then used to any extent; since then they are authorised and used by the million. I have had under observation, which calls for these remarks, cases of epithelioma, which have at earlier periods of life undergone more or less extensive treatment in the form of pure phosphorus in perles or pills. Undoubtedly the use of phosphorus has largely increased during the last twenty years; public, and I believe professional, opinion says that cancer has pari passu done the same during the same period. Arsenic I use often, and consider it of inestimable value in its proper place; phosphorus I believe to be a dangerous remedy, and it is certainly one that I can never prescribe, so great is my prejudice to it. I should be glad to hear, either privately or through your columns, any evidence that is likeiy to be in any way confirmatory of phosphorus aggravation to cancer. The benefit, too, derived from lime salts, as reported, distinctly indicates a possibility, at least, that I am not entirely in the wrong.

I am, Sirs, yours falthfully,

Rochdale, April 16th, 1888. WILIIAM STANWELL.

THE OATHS BILL.

To the Editors of THE LANCET.

Sirs,-I am surprised that no notice has been taken in your correspondence column of the annotation on the above, which appeared in a recent issue. I have repeatedly heard medical witnesses complain of the manner in which they wers sworn when giving evidence in court, and of having to kiss a greasy, dirty book. Though apparently a trivial matter, it really is not so, as it cannot be denied in these days, when so much attention is being drawn to media of contagion, that handling and kissing a book in indiscriminate use might be the medium of infection with fever or even syphilis. But nothing can be done in the way of changiag this except by an Act of Parliament. Hence, as it seems to me, advantage should be taken of the introduction of the Oaths Bill to have introduced into it a clause changing the present mode of administering the oath in this country to that used in Scotland-viz., with the right hand uplifted and by each witness repeating the words of the oath. This would be more solemn as well as more cleanly. I am, Sirs, yours faithfully,

Liverpool, April 17th, 1888. FRED. W. LOWNDES

\section{EARLY VACCINATION. To the Editors of THe LANCET.}

Sirs,-In reference to early vaccination, you will perhaps allow me to state that during the time I was medical superintendent of the Homerton (now Eastern) Small-pox Hospital, five children were born in that institution, all of whom were vaccinated within twenty-four hours of their coming into the world. This was done for obvious reasons, with the result that none contracted small-pox, although living within a few yards of wards, all of which at times were fully occupied, and certainly without producing any ill effects upon either the mental or physical condition of the children.-I am, Sirs, yours faithfully,

WM. Gayton, M.D.

Metropolitan Asylum Board, North-Western Hospital

Haverstock-hill, N.W., April 17th, 1888.

\section{DISLOCATION OF THE HEAD OF THE FIBULA. To the Editors of THB LANCBT.}

SIRs,-I quite agree with Dr. Thomson in thinking that the tenseness of the biceps tendon is the chief hindrance to the reduction of such cases; and that the first thing to be done is to relax the tendon by flexing the leg on the thigh. In my case the patient did this for himself, and, further, by forcibly extending his leg, he caused sudden tension of the biceps tendon, this pulling on the head of the fibula and doing what Dr. Thomson did in his case by the pressure of the fingers. The difference is merely that between pushing and pulling. I admit that the reduction in my case may have been effected by the pressure of Mr. Battle's thumb, which was on the dislocated head; but I do not think that it was thus effected, as the kick of the patient was quite unexpected, and occurred before Mr. Battle had attempted to reduce it; and also the snap was heard immediately after the kick, and not during it.

I am, Sirs, yours faithfully,

Walton-place, S.W., April 17th, 1888. AsHLEY LEGGATT, M.B.

\section{"HAMMER-TOE"}

To the Editors of THE LANCET.

SIRs,-I think that those who have been in the East will agree with me that no case of hammer-toe is ever seen in any people who do not wear European shoes. The entire freedom from crossing of the toes and hammer-toe in Eastern races appears to me to indicate the certainty that all such deformities are produced by the bad shape of our shoes. In the case of an infant born with a deformity of this kind the evil is no doubt hereditary, and the result of pressure of the toes in some ancestor of the child.

April 11th, 1888. I am, Sirs, yours truly, ÁNDREW FYFE,

\section{NORTHERN COUNTIES NOTES.}

(From our own Correspondent.)

THE DURHAM COUNTY ASYLUM.

Dr. SMrTH, the medical superintendent of the Durham County Asylum, has sent in a report to the magistrates on the condition and work of the institution, in which he says: "The year commenced with a population in the house of 606 men and 526 women, and ended with 616 men and 527 women, an apparent increase of only 11 patients; but 100 inmates-50 of each sex-had been sent by the superintendent to board at the Whittingham Asylum, and these may be, for statistical purposes, still considered on the books. The private cases had also been for the most part discharged, and their places occupied by union cases, so that instead of an increase of only 11 there 